\title{
Effect of Arsenic on Chloroplast Ultrastructure in Azolla filliculoides Lam
}

\author{
Zavaleta-Mancera $\mathrm{HA}^{1}$, Ortega-Ramírez $\mathrm{LG}^{3}$, Jiménez-García $\mathrm{LF}^{3}$, Sánchez-Viveros $\mathrm{G}^{4}$, Alarcón A. ${ }^{2}$ \\ ${ }^{1 .}$ Electron Microscopy Unit, ${ }^{2}$. Microbiology Laboratory, Colegio de Postgraduados, Montecillo \\ Texcoco, Estado de México, México \\ 3. Nanobiology Laboratory, Facultad de Ciencias, Universidad Autónoma de México, UNAM, México. \\ 4. Agricultural Science Department, Universidad Veracruzana, Xalapa-Veracruz, México.
}

Arsenic (As) is a toxic metalloid found in rocks, soil, water, sediments, and air. Excessive use of Asbased pesticides and indiscriminate disposal of domestic (sewage) and industrial (timber, tannery, paints, electroplating, etc.) wastes, as well as mining activities, have resulted in widespread As contamination of soils and waterways [1]. At present the maximum permissible concentration of arsenic in drinking water is $10 \mu \mathrm{g} / \mathrm{L}$ stated by the World Health Organization [2]. In Mexico the minery and the over-extraction of groundwaters are the main causes of water contamination by As, and well water contains 0.24 to $1.0 \mathrm{ppm}$ As in several communities, for example, $1.097 \mathrm{mg}$ As/L groundwater in La Comarca Lagunera, San Luis Potosí and Zimapán, Hidalgo. This is a major problem for México and cancer is the most striking long term effect of chronic exposure to inorganic arsenic [3]. Azolla filiculides is reported as an aquatic fern able to grow in water contaminated with As and accumulate $\mathrm{As}^{+5}$; thus, it can be used for phytoremediation [4].

The objective of our research was to investigate the effect of As on chloroplast ultrastructure of $A$. filiculides exposed to increasing concentration of As. Plants were incubated on the nutritious solution Yoshida $\mathrm{pH}$ 5, [5] added with 5, 10, 20 y $30 \mu \mathrm{g} \mathrm{mL}{ }^{-1}$ sodium arsenate $\left(\mathrm{Na}_{2} \mathrm{HAsO}_{4} \cdot 7 \mathrm{H}_{2} \mathrm{O}\right.$, SigmaAldrich) and $0 \mu \mathrm{g} \mathrm{mL}{ }^{-1}$ as control during $96 \mathrm{~h}$ in growth chamber $\left(26{ }^{\circ} \mathrm{C}, 12 \mathrm{~h}\right.$ photoperiod, and light $\left.280 \mu \mathrm{mol} \mathrm{cm} \mathrm{cm}^{-2}\right)$. Transversal leaf sections $\left(1 \mathrm{~mm}^{2}\right)$ of the leaf were fixed in glutaraldehyde $2.5 \%$ in buffer Sorensens $\left(0.1 \mathrm{M}, \mathrm{pH}\right.$ 7.2) under vacuum at $4{ }^{\circ} \mathrm{C}$ for $24 \mathrm{~h}$ and a post-fixation with $1 \%$ osmium tetroxide for $2 \mathrm{~h}$. Samples were processed and included in LR-White resin (London Resin Company, UK). Fine sections (80-100 $\mathrm{nm}$ ) were contrasted with uranyl acetate $(1 \%)$ and lead citrate solution, and they were observed under a TEM microscope (JEOL JEM 1010, Japan) at $80 \mathrm{Kv}$.

Chloroplast from control fronds were oval shape, smooth and intact external double membranes, well preserved grana thylakoids and electron opaque stroma (Fig. 1 A-B), which is a typical structure of a healthy and functional chloroplast. Chloroplast structure from leaves treated with $5 \mu \mathrm{g} \mathrm{mL}^{-1}$ As was not affected by the metalloid but some small dark precipitates appeared close to the tonoplast (Fig. 1 C). Chloroplasts treated with $10 \mu \mathrm{g} \mathrm{mL}^{-1}$ arsenate showed swelling external and thylakoid membranes, reduction of the electron opacity in some areas of stroma, and shape of the plastid was modified (Fig. 1 D). Chloroplasts from leaves treated with $20 \mu \mathrm{g} \mathrm{mL}^{-1}$ arsenate were characterised by the presence of starch grains and abundant dark precipitates (Fig. 1 E). The larger disturbance of chloroplast structure was observed at $30 \mu \mathrm{g} \mathrm{mL} \mathrm{m}^{-1}$ arsenate (Fig. $1 \mathrm{~F}$ ). Chloroplasts lost its elongated shape and appeared round with irregular external membrane. Internal thylakoids were disorganised and disintegrated; grana thylakoids lost its arrangement and some thylakoids appeared single and dispersed in faint stroma (Fig. 1 F). Some plastids were broken and they appeared as amorphous grey mass with some fragments of thylakoids without organization. The sequence of events observed in A. filiculoides chloroplasts treated with 5, 10 and $20 \mu \mathrm{g} \mathrm{mL}^{-1}$ arsenate remind the changes in structure observed in Pteris vittata L., a hyperaccumulator fern, produced by addition of arsenate $\left(0,100,300\right.$ and $\left.800 \mathrm{mg} \mathrm{kg}^{-1}\right)$ to dry soil for 
24 weeks in a greenhouse [6]. But in our study, treatment with $30 \mu \mathrm{g} \mathrm{mL}^{-1}$ arsenate, largely affected the structure of chloroplasts, more than in P. vittata, suggesting an extended damage of the photosynthetic activity.

\section{References:}

[1] MA Armienta et al, Hydrogeology Journal 5 (1997), 39-46.

[2] WHO, World Health Organization. Arsenic: Environmental Health Criteria 18: International

Programme on Chemical Safety, Geneva (2002), 174 p.

[3] JR Parga et al, Journal of Hazardous Materials 124 (2005), 247-254.

[4] A Sood et al, Ambio 41 (2012), 122-137.

[5] S Yoshida et al, "Laboratory manual for physiological studies of rice" 3th ed. International Rice Institute, Manila Philippines (1971).

[6] WX Li et al, Chemosphere 62 (2006), 803-809.
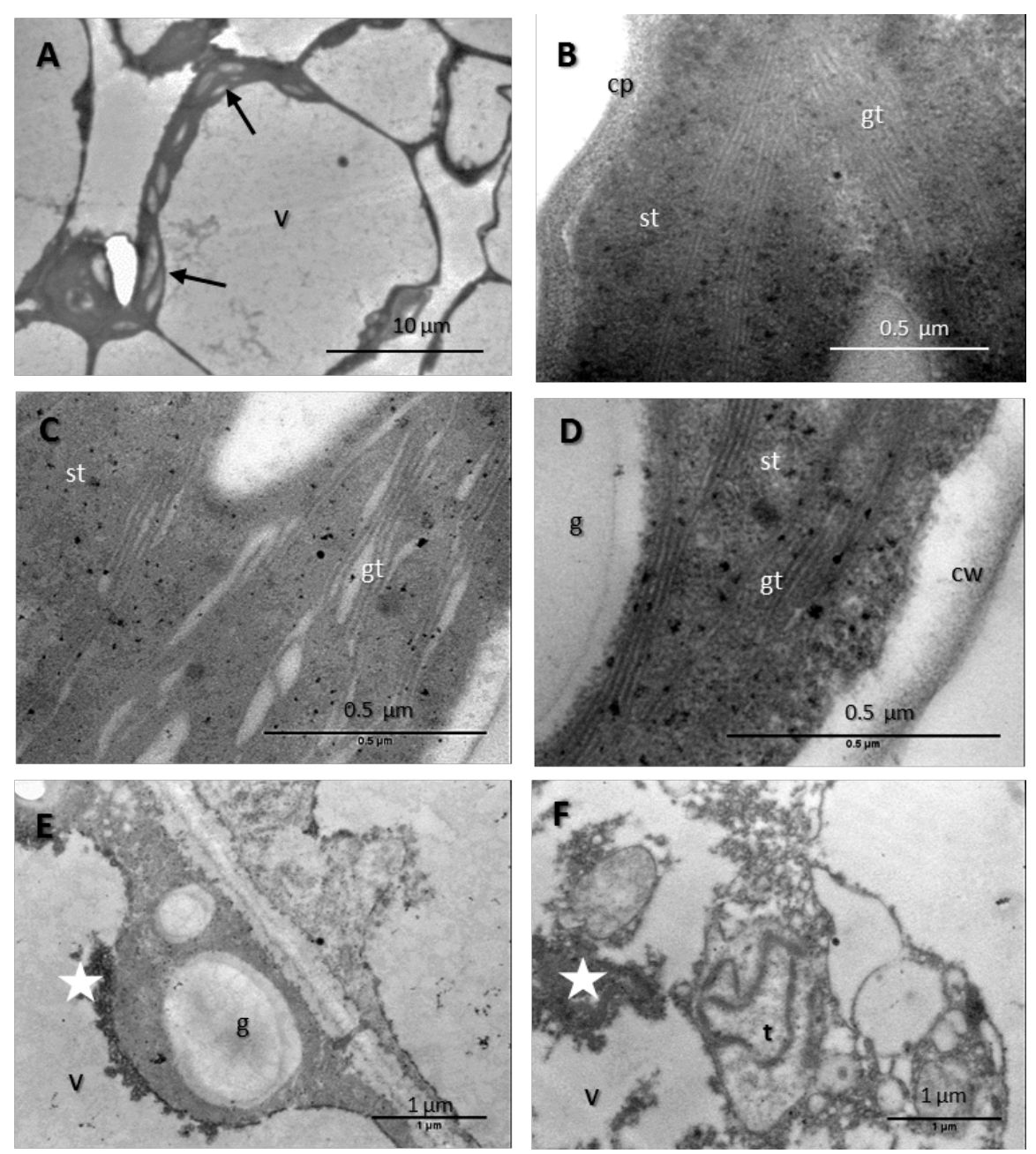

Figure 1. TEM images of Azolla filiculoides chloroplasts exposed to increasing concentrations of arsenate. A- B) control; C) $5 \mu \mathrm{g} \mathrm{mL}^{-1}$ As, D) $10 \mu \mathrm{g} \mathrm{mL}^{-1}$ As; E) $20 \mu \mathrm{g} \mathrm{mL}^{-1}$ As; F) $20 \mu \mathrm{g} \mathrm{mL}^{-1}$ $\mathrm{cp}=$ cytoplasm; $\mathrm{cw}=$ cell wall; $\mathrm{g}=$ starch grain; $\mathrm{gt}=$ grana thylakoid; $\mathrm{st}=$ stroma $\mathrm{t}=$ thylakoid, $\mathrm{v}=$ vacuole; arrows indicate chloroplasts, white stars indicate precipitates. 